\title{
WILD FIRE AEROSOL OPTICAL PROPERTIES MEASURED BY LIDAR AT HAIFA, ISRAEL
}

\author{
Birgit Heese $^{1, *}$, Julian Hofer ${ }^{1}$, Holger Baars ${ }^{1}$, Ronny Engelmann ${ }^{1}$, Dietrich Althausen ${ }^{1}$ and \\ Yoav Y. Schechner ${ }^{2}$
}

\author{
${ }^{1}$ Leibniz Institute for Tropospheric Research - TROPOS, Germany, *heese@tropos.de \\ ${ }^{2}$ Technion - Israel Institute of Technology, Israel
}

\begin{abstract}
Optical properties of fresh biomass burning aerosol were measured by lidar during the wild fires in Israel in November 2016. A singlewavelength lidar Polly was operated at the Technion Campus at Haifa. The detector with originally two channels at 532 and $607 \mathrm{~nm}$ was recently upgraded with a cross- and a copolarised channel at $532 \mathrm{~nm}$, and a rotational Raman channel at $530.2 \mathrm{~nm}$. Preliminary results show high particle depolarisation ratios probably caused by soil dust and large fly-ash particles.
\end{abstract}

\section{INTRODUCTION}

Wild fires in Israel started on 22 November 2016 and lasted until 25 November 2016. They were reported at several spots around the country, but the largest ones spread across Haifa. The view from the satellites perspective (Fig. 1) clearly shows the smoke plume from the fires stretching out from Haifa onto the Mediterranean. The fires had coincided with strong and dry easterly winds. The wind direction and speed during the wild fires measured at Haifa University are shown in Fig. 2. Easterly winds set in on 19 November and the wind speed increased significantly during that week. On 24 November, maximum wind gusts up to $70 \mathrm{~km} / \mathrm{h}$ were measured. This was the day with the strongest fires in Haifa. This incident offers the opportunity to study fresh wild fire optical properties with the recently installed Polly lidar at Haifa.

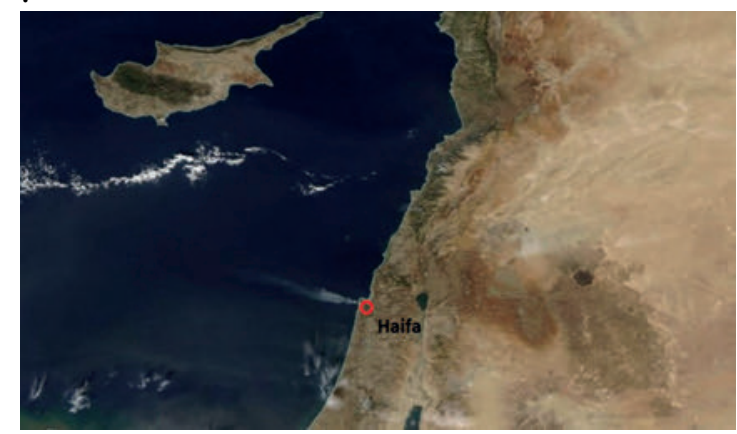

Figure 1: MODIS image on 24 November 2016 at 11:06 UTC (https://earthdata.nasa.gov).

\section{METHODOLOGY}

The lidar measurements at Haifa, Israel are performed by TROPOS since late July 2016 in collaboration with the Viterby Faculty of Electrical Engineering at the Technion. The deployed lidar is the first single-wavelength Polly built in 2003. The lidar was recently upgraded. Originally it had two channels at 532 and $607 \mathrm{~nm}$. After the upgrade it now has one cross- and one co-polarised channel at $532 \mathrm{~nm}$, and one rotational Raman channel at $530.2 \mathrm{~nm}$. Thus, it is now capable to measure the linear particle depolarisation ratio profile in addition to the particle backscatter and extinction coefficient profiles. Using these profiles and collocated sun photometer measurements, we are able to apply the polarization-lidar photometer networking (POLIPHON) method [1] to separate coarse and fine mode particles in the vertical profile. 


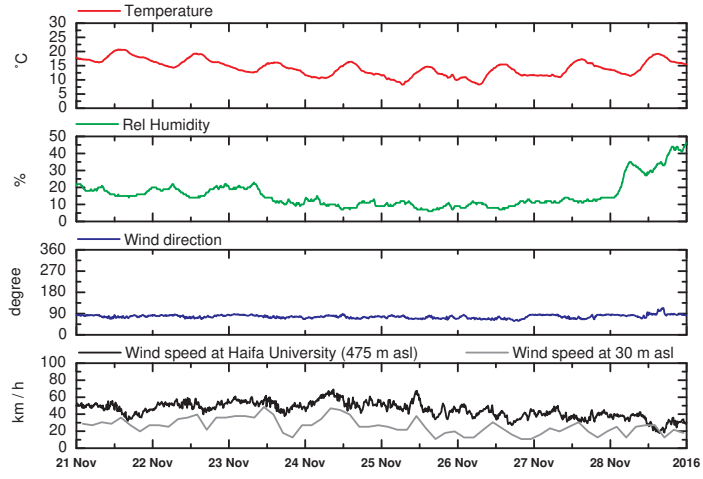

Figure 2: Temperature, relative humidity, wind speed, and wind direction measured at Haifa University on 21 - 28 November 2016. (Israel Meteorological Service)

During daytime, the particle backscatter and extinction coefficient profiles are calculated using the Klett method [2] (lidar ratio $=60 \mathrm{sr}$, vertical smoothing: $82.5 \mathrm{~m}$ ). During night-time the Raman method [3] was applied (vertical smoothing: $307.5 \mathrm{~m}$ ). For molecular corrections we used radio soundings from the station Bet Dagan of the Israel Meteorological Service (IMS), which is close to Tel Aviv airport. The linear particle depolarisation ratio is derived using regular, internal calibration measurements following the EARLINET quality assurance standards [4].

\section{RESULTS}

On 25 November 2016, one day after the major fires in Haifa, high values of the range-corrected lidar signal were observed (see Fig. 3). The measurements started at 7:47 UTC, when the evolution of the boundary layer was already in progress. High backscatter signals can be seen in the lower boundary layer up to about $1 \mathrm{~km}$ height over the measurement site - especially before 11 UTC. Also the respective profiles of particle backscatter coefficient (Fig. 4) show comparatively high values of up to $5.5 \mathrm{Mm}^{-1} \mathrm{sr}^{-1}$. This is twice as much as

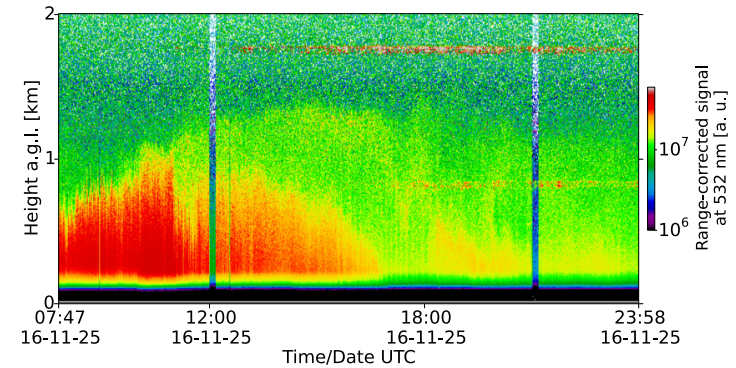

Figure 3: Range corrected lidar signal on 25 November 2016 measured at Haifa. The vertical low-signal bars at 12 and 21 UTC are due to calibration periods. Horizontal stripes are artefacts.
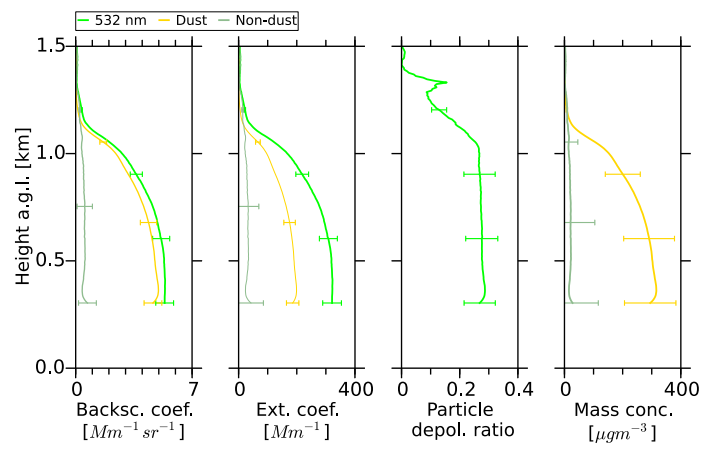

Figure 4: Profiles of particle backscatter and extinction coefficient, linear particle depolarization ratio, and mass concentration (from left to right) at $532 \mathrm{~nm}$, separated into dust and non-dust fractions on 25 November 2016, 10:00-11:00 UTC.

observed on the days before and the following days. Then the values of the particle backscatter coefficient were about $2-2.5 \mathrm{Mm}^{-1} \mathrm{sr}^{-1}$. The particle extinction coefficient values were calculated using a lidar ratio of $60 \mathrm{sr}$, assuming a mixture of pollution, burning, and dust particles, which leads to a value of about $300 \mathrm{Mm}^{-1}$ on that day. On the days before and after the fire period, the particle extinction coefficients were around $150 \mathrm{Mm}^{-1}$, including the ones derived from Raman measurements. As a preliminary step to identify different particle types, we applied the POLIPHON method to separate the 
particle backscatter coefficient profile into dust and non-dust contributions.

This method uses the measured particle linear depolarisation ratio, which was as high as 0.26 0.27 in the lower boundary layer on this day. For the separation into dust and non-dust particle backscatter coefficients, a linear particle depolarisation ratio of 0.31 for dust particles and 0.05 for non-dust particles was assumed. These values are derived from several previous measurement campaigns. The conversion into mass concentration is then realized by applying particle specific extinction-to-mass conversion factors based on prior long-term sun photometers observations and AERONET data analysis (see [5] and references therein for details).

These preliminary results lead to the conclusion, that a considerable amount of large particles must have been present in the atmosphere during the wild fires. These large particles are possibly soil dust and flying ash lifted into the atmosphere by the observed strong easterly winds and by turbulence associated with the fires. Dust from the desert regions east of Israel may also have been transported by the winds towards the coast regions.

HYSPLIT $24 \mathrm{~h}$ back-trajectory calculations for arrival time of 11:00 UTC (Fig. 5) show that the air masses at the lower altitudes of $500 \mathrm{~m}$, $1000 \mathrm{~m}$ and $2000 \mathrm{~m}$ height are coming from the regions east and north-east of Haifa.

An example of a lidar measurement after the fire period is shown in Fig. 6. On 28 November during daytime, the boundary layer starts to develop around 06:00 UTC and is reaching up to about $2 \mathrm{~km}$ in the evening. The upper part of the boundary layer persists as the residual nighttime layer, while the lower part is decaying slightly towards midnight. Fig. 7 shows the corresponding lidar profiles for the measurement period from 18:00-20:00 UTC. The values of the particle backscatter coefficient were

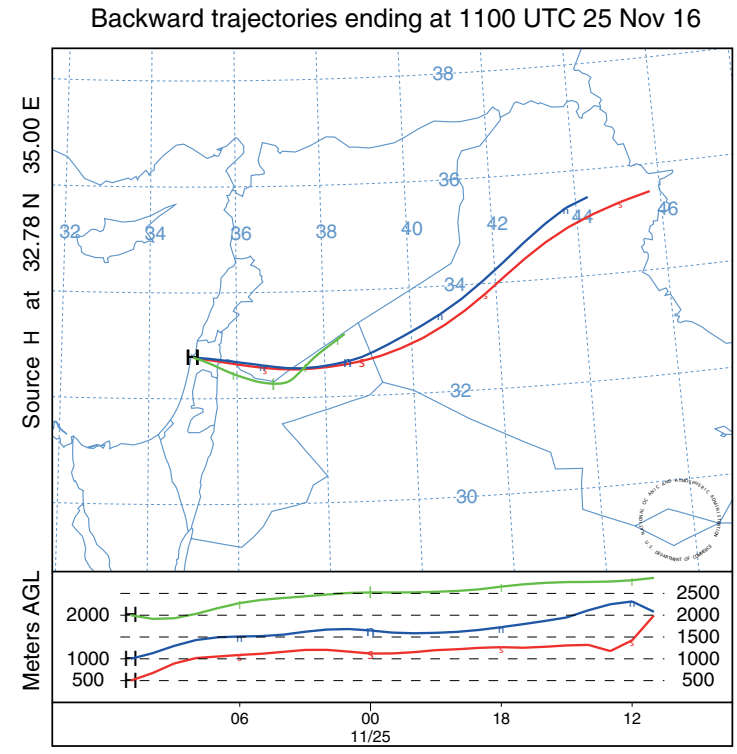

Figure 5: HYSPLIT backward trajectories ending at Haifa on 25 Nov. 2016 at 11:00 UTC.

between $2 \mathrm{Mm}^{-1} \mathrm{sr}^{-1}$ and $3 \mathrm{Mm}^{-1} \mathrm{sr}^{-1}$ in the lower boundary layer and drop slowly below $2 \mathrm{Mm}^{-1} \mathrm{sr}^{-1}$ above $1 \mathrm{~km}$ height.

The particle extinction coefficients are around $150 \mathrm{Mm}^{-1}$ below and $100 \mathrm{Mm}^{-1}$ above $1 \mathrm{~km}$ height. Because it was evening, the lidar ratio profile could be calculated using the Raman method. The lidar ratio is rising from $50 \mathrm{sr}$ to $60 \mathrm{sr}$ in the lower layer and is $40 \mathrm{sr}$ in the residual boundary layer. The linear particle depolarisation ratio increases from values of 0.15 in the lower boundary layer up to 0.2 at the top at $2 \mathrm{~km}$ height. These high values indicate a non-negligible part of coarse mode particles present above the measurement site. However, the conversion into dust and non-dust particle contributions show that the dust mass concentration has decreased from about $300 \mu \mathrm{gcm}^{-3}$ on 25 November to $60 \mu \mathrm{gcm}^{-3}$ on 28 November. This is less than a third of the amount of large particles than during the wild fires. 


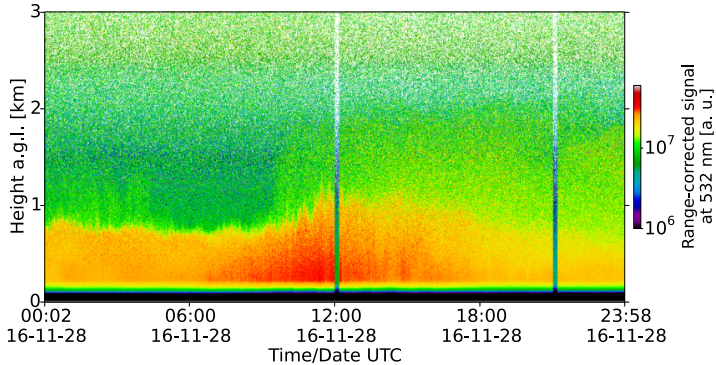

Figure 6: Range-corrected lidar signal on 28 November 2016 measured at Haifa. The vertical low-signal bars at 12:00 and 21:00 UTC are due to calibration periods. Note that the height scale ranges to $3 \mathrm{~km}$ in this graph.

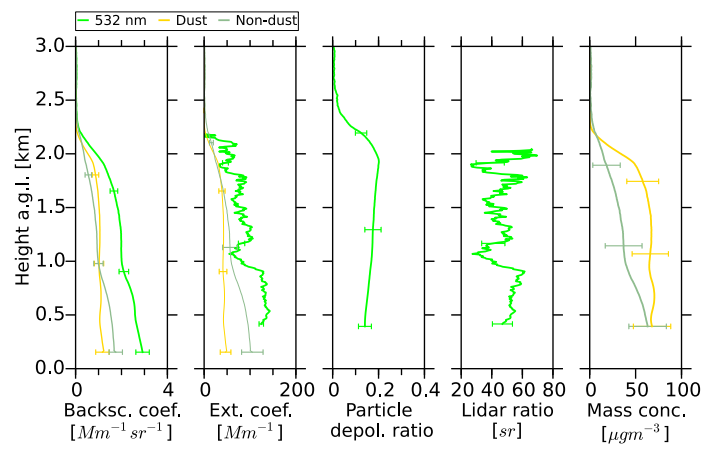

Figure 7: Profiles of particle backscatter and extinction coefficient, linear particle depolarization ratio, lidar ratio, and mass concentration (from left to right) at $532 \mathrm{~nm}$, separated into dust and non-dust fractions on 28 November 2016 , 18:00-20:00 UTC. These profiles were calculated using the Raman method.

\section{CONCLUSIONS}

These analyses are still preliminary. Separation into different particle contributions to the lidar properties will be extended, including further separation into fine and coarse mode dust. In March 2017 the one wavelength Polly at the Technion site in Haifa was replaced by a multiwavelength Polly ${ }^{X T}$ lidar of the new generation [6]. This will allow for more comprehensive lidar data retrievals and a larger set of optical par- ticle properties, including lidar ratios and depolarisation ratios at two wavelengths as well as the respective Ångström exponents.

\section{ACKNOWLEDGEMENTS}

We are grateful to Rotem Zamir, Vadim Holodovsky and Amit Aides for assistance in the lidar operation in Haifa. This project is funded by the GermanIsraeli Foundation (GIF grant I-1262-401.10/2014) with support of the Norman and Helen Asher Fund. The work of Yoav Y. Schechner is conducted in the Ollendorff Minerva Center. Minerva is funded through the BMBF (German federal ministry for education and research). TROPOS has also received funding from the European Union's Horizon 2020 research and innovation programme under grant agreement No 654109.

\section{References}

[1] Mamouri, R.E. and A. Ansmann, 2014: Fine and coarse dust separation with polarization lidar, Atmos. Meas. Tech. 7, 3717-3735.

[2] Klett, J. D., 1981: Stable analytical inversion solution for processing lidar returns, Appl. Optics 20, 211-220.

[3] Ansmann A., et al., 1992: Independent measurement of extinction and backscatter profiles in cirrus clouds by using a combined Raman elastic-backscatter lidar, Appl. Opt. 31, 7113-7131.

[4] Freudenthaler V., et al., 2009: Depolarization ratio profiling at several wavelengths in pure Saharan dust during SAMUM 2006. Tellus 61B, 165-179.

[5] Mamouri, R.E. and A. Ansmann, 2017: Potential of polarization/Raman lidar to separate fine dust, coarse dust, maritime, and anthropogenic aerosol profiles, in preparation.

[6] Engelmann, R., et al., 2016: The automated multiwavelength Raman polarization and water-vapor lidar PollyXT: the neXT generation, Atmos. Meas. Tech. 9, 1767-1784, doi:10.5194/amt-9-1767-2016. 